Thorax (1968), 23, 541.

\title{
Strangulated diaphragmatic hernia
}

\author{
EUGENE HOFFMAN
}

From the Thoracic Surgery Unit, Poole Hospital, Middlesbrough

\begin{abstract}
Seventy-six cases of strangulated diaphragmatic hernia were reported up to 1953. An additional 64 cases reported between 1953 and 1966 are reviewed in this paper. The incidence of strangulation in various types of congenital/traumatic, hiatal, and incisional herniae is discussed. Four further cases of strangulated diaphragmatic hernia are presented. The mechanism of strangulation, its diagnosis, complications, and treatment are discussed.
\end{abstract}

Strangulation commonly occurs in most herniae but it is rare in the diaphragmatic variety. The term 'strangulation' should only be used in cases where the blood supply of the prolapsed viscera is impaired. Because of the rarity of this condition individual authors often report only single cases. There have been two comprehensive reviews of cases published up to 1953. I intend to review the literature since 1953, adding four cases of my own, and to consider the clinical problems of strangulation in the various types of diaphragmatic hernia.

\section{INCIDENCE}

Carter and Giuseffi (1948) collected all reported cases of strangulated diaphragmatic hernia from 1798 to 1948. Pearson (1953) added a further 33 cases from the literature up to 1953. From 1953

\section{T A B L E I}

INCIDENCE OF STRANGULATED DIAPHRAGMATIC

\begin{tabular}{|c|c|c|c|c|c|c|}
\hline \multicolumn{5}{|c|}{ Author } & \multirow{2}{*}{$\begin{array}{c}\text { Years } \\
1798-1948 \\
1948-1953 \\
1953-1966\end{array}$} & \multirow{2}{*}{$\begin{array}{c}\text { No. of Cases } \\
43 \\
33 \\
64\end{array}$} \\
\hline $\begin{array}{l}\text { Carter an } \\
\text { Pearson } \\
\text { Hoffman }\end{array}$ & $\begin{array}{l}\text { Giuseffi } \\
\ldots \\
\ldots\end{array}$ & $\begin{array}{l}. \\
\cdots\end{array}$ & $\begin{array}{l}. . \\
\cdots\end{array}$ & \begin{tabular}{l|}
$\ldots$ \\
$\cdots$ \\
$\cdots$
\end{tabular} & & \\
\hline \multicolumn{4}{|c|}{ Total } & $\cdots$ & & 140 \\
\hline
\end{tabular}

to 196664 cases were published in 40 papers (Table I). This included only those in which the pathological features of strangulation were found at operation or necropsy. In a number of other papers it was clear that only obstruction or incarceration had occurred.

\section{DISTRIBUTION}

Strangulation can occur in both congenital and acquired diaphragmatic herniae. Carter and Giuseffi (1948) stated that in $90 \%$ of cases with strangulation the hernia was of the traumatic variety. This statement has been accepted by most authors who have written on this subject. Indeed, Harrington (1948), reviewing 430 cases of diaphragmatic hernia, stated that he had never seen gangrene of the stomach in a hiatus hernia. More recent reports (since 1953) show that strangulation is just as frequent in hiatus hernia as in traumatic cases (Table II). A number of cases have also been reported of strangulation through the diaphragmatic incision after repair of hiatus hernia (Table II).

\section{T A B L E I I}

TYPES OF DIAPHRAGMATIC HERNIA IN WHICH STRANGULATION OCCURRED

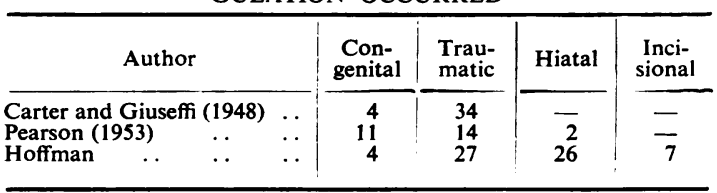

CONGENITAL HERNIA In congenital hernia strangulation is rare. In most herniae there is free communication between the pleural and peritoneal cavities. Occasionally the defect is only muscular, and these patients may develop a hernia in later life in a sac of serous membranes. In Bingham's (1959) review of 11 children with posterolateral congenital hernia only two had a hernial sac. He describes three types of congenital diaphragmatic defects-posterolateral, retrosternal, and extensive defects involving most of the hemidiaphragm. 
Posterolateral defects are the commonest. They comprised 323 out of 376 cases of congenital hernia in Pilcher's (1965) series and are nearly always on the left. Strangulation of such a hernia in an infant is rare because, if untreated, they usually die within the first few days of life of cardiorespiratory embarrassment. The youngest patient with strangulation was described by Rickham (1955), an infant of 2 weeks. Patients with posterolateral hernia may survive and be discovered in adult life. Kirkland (1959) collected reports of 34 patients with an average age at diagnosis of 39 years. In several of these, acute obstructive attacks occurred without previous symptoms. Strangulation in retrosternal defects is exceptional. In none of the 50 patients with this condition operated on by Comer and Clagett (1966) was strangulation present.

Traumatic rupture of the diaphragm at sites where congenital hernia usually occurs is difficult to differentiate, as the sac is usually absent in both and there may be no clear history of trauma.

TRAUMATIC HERNIA Traumatic diaphragmatic hernia is due to direct or indirect violence.

The proportion of direct penetrating injuries due to stab, bullet or shrapnel wounds varies in different countries and is low in the United Kingdom. In these cases the tear is small and strangulation may occur. Ambroise Paré (1510-1590) was the first to describe strangulation of a diaphragmatic hernia. He recorded the case of a mason who was wounded in the diaphragm and died on the third day. On performing a necropsy he found that the stomach had herniated into the chest through a wound which would admit only a thumb (Allison, 1962). Recently, Sullivan (1966) reviewed 53 cases of obstruction or strangulation following direct diaphragmatic injury, mostly stab wounds occurring over a period of 14 years.

Indirect diaphragmatic injuries are caused by sudden compression of the abdomen or chest with or without rib fractures, such as falls from heights, compression injuries, or blows. They most commonly occur, however, in car accidents, particularly with steering wheel injuries, and these cases are increasing. Of 112 patients who were operated on for ruptured diaphragm at the Mayo Clinic, 78 were due to car accidents (Bernatz, Burnside, and Clagett, 1958). The tear is usually on the left, as the liver protects the right diaphragm. In Childress and Grimes' (1961) series the rupture was on the right in only two of 25 patients. Early strangulation in indirect traumatic hernia is rare as the defect is usually a large one. Occasional cases have been reported, such as that of a 68 -year $\frac{\text { 을 }}{=}$ old woman who died 48 hours after being struck $\frac{\bar{c}}{\sqrt{5}}$ by a car. At necropsy a prolapsed gangrenous ${ }^{\Phi}$ stomach with perforation was found (Sutherland, 1958). Moos' (1956) patient also developed gan-grene of the stomach 48 hours after injury, but recovered following partial gastrectomy.

Rupture of the diaphragm is often overlooked at the time of injury, and strangulation may only $\vec{x}$ occur some time later. In my patient (case 2) the injury had occurred 15 years previously. Knight and McCook (1960) reported a patient who devel-ir oped strangulation of the colon 20 years after the $\$$ original injury. Symptoms are present in the majority of patients following diaphragmatic injury ; Bernatz et al. (1958) reported symptoms incs 91 out of 112. These patients may complain of vague upper abdominal distress aggravated by eating, pain in the upper abdomen or lower chest, and shortness of breath.

HIATAL HERNIA Oesophageal hiatus hernia is byळ far the commonest type of diaphragmatic hernia, and of these $90 \%$ are sliding herniae in which strangulation is rare. It occurs more commonly in the paraoesophageal variety, which is a con-0 genital hernia. Here there is a preformed peri-市 toneal sac in front of the oesophagus into which the stomach rolls, so that the greater curvatureo응 comes to lie uppermost, and this partial torsion predisposes to acute obstruction or strangulation. Paraoesophageal hernia differs from the sliding variety in that reflux oesophagitis and its complications do not occur because of the increased angulation between the oesophagus and the stom- $-x$ ach. Beardsley and Thompson (1964) reported 5373 cases of hiatus hernia, 13 of which developedo acute obstruction of the stomach; 12 of these 3 were paraoesophageal and one a combination of 0 sliding and paraoesophageal herniae. Strangulation of the stomach with perforation occurred in only one case, and that patient died post-operatively. Belsey (1965) described fatal complica- $\widetilde{N}$ tions which may occur in paraoesophageal hernia, N which he calls type II hernia. Of 21 patients forN whom no operation was advised because of the ${ }_{\sigma}^{\omega}$ mildness of symptoms, six died, two from torsion and gangrene of the intrathoracic stomach, three? from gastric haemorrhage, and one from suffoca- $-\infty$ tion due to acute dilatation of the prolapsed stomach. These and other reports suggest that a para- -0 oesophageal hernia should be repaired as soon as it is diagnosed even if the patient is symptom-free. $\frac{?}{\mathbb{D}}$

INCISIONAL HERNIA Prolapse of viscera into the $\bar{\sigma}$ chest through the diaphragmatic incision used in 


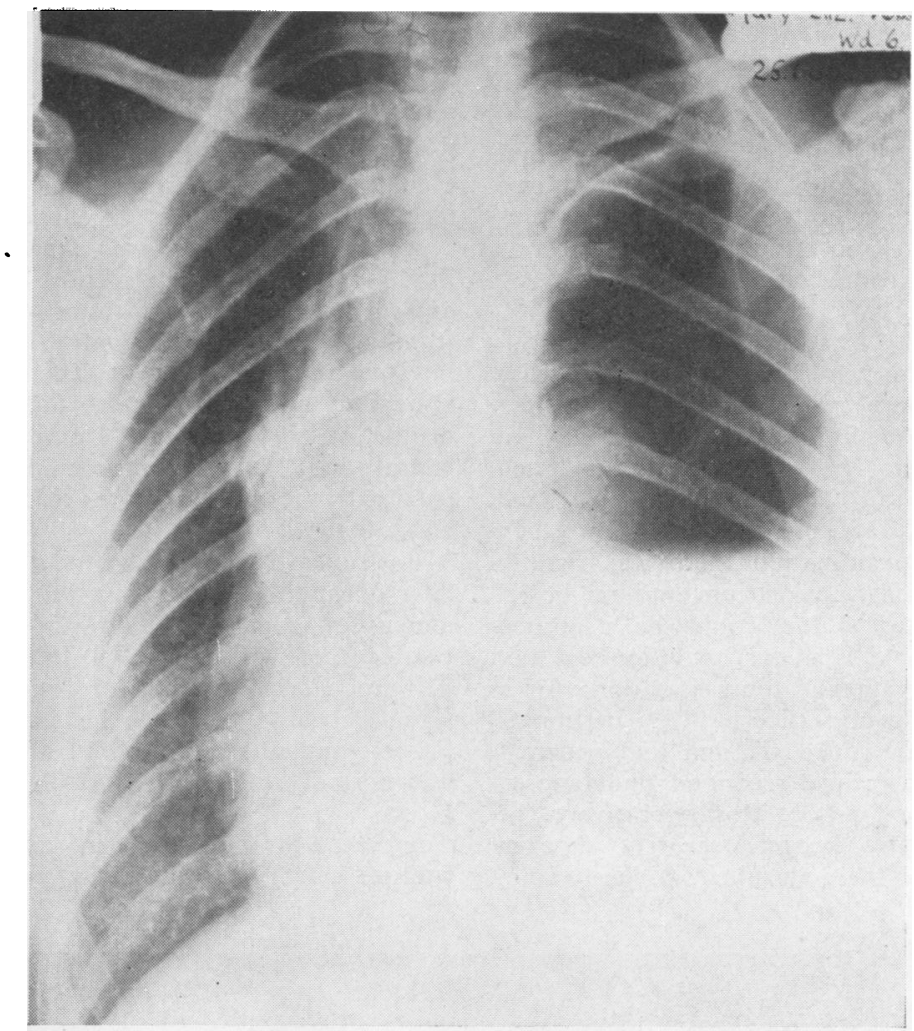

FIG. 1. Case 1. Chest film on admission showing a distended intrathoracic stomach with fluid level and displacement of the mediastinum to the right.

the repair of hiatus hernia has recently been reported. Effler (1965) reviewed 16 such cases reported by seven surgeons. Strangulation has also occurred in this type of case, and I include seven such cases from the literature (Table II). Two of these were reported by Keshishian and Magovern (1958): in one, resection of a gangrenous stomach was carried out one week after the repair of a hiatus hernia; in the second, the blood supply of the stomach was adequate and resection was unnecessary. Coppinger (1960) also carried out a successful resection of a gangrenous stomach six and a half months after a hiatal repair. Effler (1965) suggested that incision of the diaphragm should be abandoned, but Allison (1962) stressed that this complication need not occur if a careful diaphragmatic suture is carried out, every stitch passing through pleura, fibromuscular layer, and peritoneum.

\section{CASE REPORTS}

CASE 1 STRANGUlated CONGENITAL HERNIA This woman of 48 years gave a history of sudden pain in the chest while she was dancing. This happened following a light meal of sandwiches and a glass of wine. She was able to walk home, but stayed in bed for a week. During this time the intensity of the pain varied and she vomited occasionally. She also complained of tightness of the chest and was short of breath. On admission to a medical ward her chest radiograph (Fig. 1) was first thought to show a tension hydropneumothorax. On the day following admission she collapsed with signs of profound shock. On draining the chest a large amount of offensive fluid was obtained which was found to be of acid reaction, suggesting the presence of an intrathoracic stomach. A radiograph taken after this partial decompression showed two fluid levels, one in the pleura and the second in the stomach. She was then transferred to the Thoracic Surgical Unit, where a thoracotomy was carried out. The pleural cavity contained a large amount of serosanguineous fluid and the greatly dilated stomach, which was congested, oedematous, and purple. The spleen, part of the transverse colon, and omentum were also present in the chest. There was no hernial sac. The stomach was decompressed through an aspirating needle and the herniated viscera were reduced into the abdomen. The hiatal 
orifice, about 2 in. $(50 \mathrm{~mm}$.) long in the posterolateral part of the diaphragm, was repaired. She made an uneventful recovery.

Comment This patient had no history of trauma and her dancing was unlikely to have caused a ruptured diaphragm. She had no symptoms suggesting a preexisting hernia. It seems most probable that this was strangulation of a congenital hernia.

CaSe 2 Strangulated traumatic hernia A 33year-old man was admitted to a surgical ward with 9 hours' history of severe epigastric and left shoulder pain which started suddenly 1-2 hours after he had drunk 6 pints of beer. He vomited without much relief and continued to retch persistently. He had previously had attacks of epigastric pain, but they were less severe. On examination there was rigidity and tenderness in the left epigastrium and no bowel sounds could be heard. Little could be aspirated through a Ryle's tube and, as his condition did not improve for $\mathbf{2 4}$ hours, a laparotomy was done for a suspected perforated peptic ulcer. The peritoneal cavity showed a blood-stained effusion and oedematous mesentery, but the cause remained undiagnosed and the abdomen was closed. Post-operatively, he quickly deteriorated and became severely shocked within 2-3 hours. I was then consulted. A chest radio- graph (Fig. 2) showed a grossly dilated stomach wit|f a fluid level and displacement of the mediastinum to the right. The stomach was drained through the ches wak via an intercostal tube, and about 3 pints of foul fluid were obtained. His condition improved an a subsequent radiograph (Fig. 3) showed a centrat mediastinum and a less distended stomach.

At thoracotomy a large amount of blood-stained $\vec{r}$ fluid was found in the pleural cavity. The engorgew and distended stomach almost filled the chest; the transverse colon and about $6 \mathrm{ft}$. $(1.8 \mathrm{~m}$.) of smali intestine were also present. There was no hernial sacw Omentum and viscera were adherent to the herniair orifice, which was 2 in. $(50 \mathrm{~mm}$.) long in the posteros lateral part of the diaphragm. The orifice was enlarged, the viscera were reduced, and the defect was repaired.

Post-operative convalescence was uneventful. OrS later questioning he told us that he had suffered frono increasing epigastric pain ever since an accident 1 (DD years earlier, when he fell $40 \mathrm{ft}$. (12 m.) off a roof, and was treated in hospital for four months for a frac@ tured pelvis. After this he spent two years in the Forces, and a radiograph of the chest at that time
was normal.

Comment Strangulation in an old diaphragmatie rupture can be overlooked if a history of previous

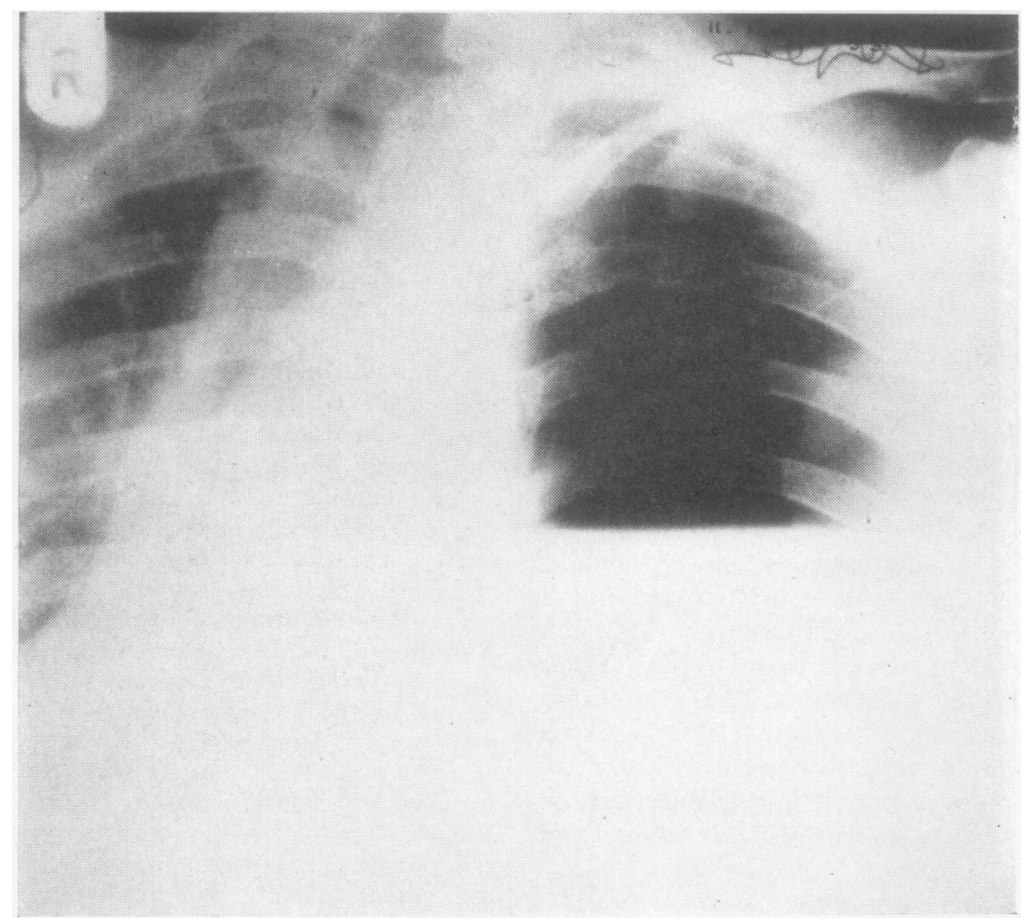

FIG. 2. Case 2. Chest radiograph after exploratory laparotomy showing a grossly distended stomach with fluid level and displacement of the mediastinum to the right. 


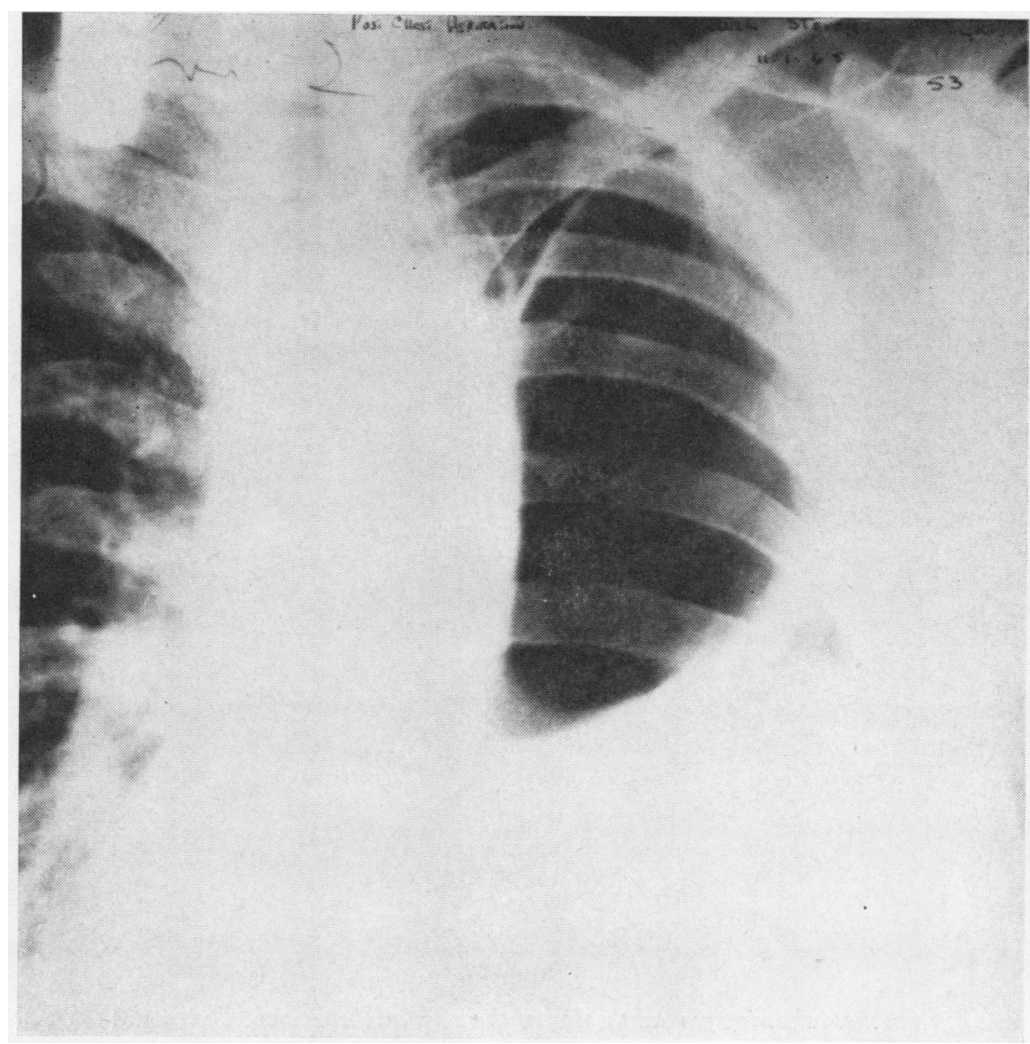

FIG. 3. Case 2. After intercostal drainage there is less gastric distension and a more central mediastinum.

injuries is not obtained, as patients often do not volunteer such information. Fractures of the lower ribs, pelvis or lumbar vertebrae are of particular importance, as they may be associated with a diaphragmatic tear. Carlson, Diveley, Gobbel, and Daniel (1958) reported that of nine patients admitted with traumatic rupture of the diaphragm, six had fractures of the pelvis or lumbar vertebrae.

A radiograph of the chest should always be taken in upper abdominal emergencies, and would have established the diagnosis in the case just described.

Treatment by decompression of the distended stomach with a tube introduced through the chest wall is an unorthodox but at times life-saving procedure, as in these cases it is often impossible to pass a stomach tube.

The next two patients were admitted with an acutely obstructed diaphragmatic hernia. The symptoms were very severe, suggesting strangulation. In both cases gastric decompression produced a remission of symptoms before repair of the hernia was carried out.

CASE 3 Strangulated CONGenital hernu A man of 40 years was admitted to a general surgical ward with acute epigastric pain which came on after he had eaten a large meal and drunk several pints of beer. On admission he was severely shocked and there was tenderness and rigidity in the epigastrium. At laparotomy the stomach was found to be distended and incarcerated in the chest. The distended stomach was decompressed with a stomach tube and the abdomen was closed. The acute symptoms subsided and he was later referred to our unit.

On admission a barium meal showed a diaphragmatic hernia with partial torsion of the herniated stomach (Figs 4 and 5). At thoracotomy there was a large hernia with a sac. It contained most of the stomach, which was rotated with the greater curvature uppermost. The defect was about 4 in. $(10 \mathrm{~cm}$.) in diameter in the parahiatal position. There was a solid wedge of lung tissue about $3 \mathrm{in}$. $(7 \cdot 6 \mathrm{~cm}$.) long lying free in the paravertebral gutter just above the diaphragm. It had no connexion with the bronchi, and the arterial supply came from the abdominal aorta and passed through the hernial orifice. This sequestrated lobe was removed and the hernia was repaired. Convalescence was uneventful.

Comment The predisposing cause here was torsion of the stomach, and the acute attack was precipitated 

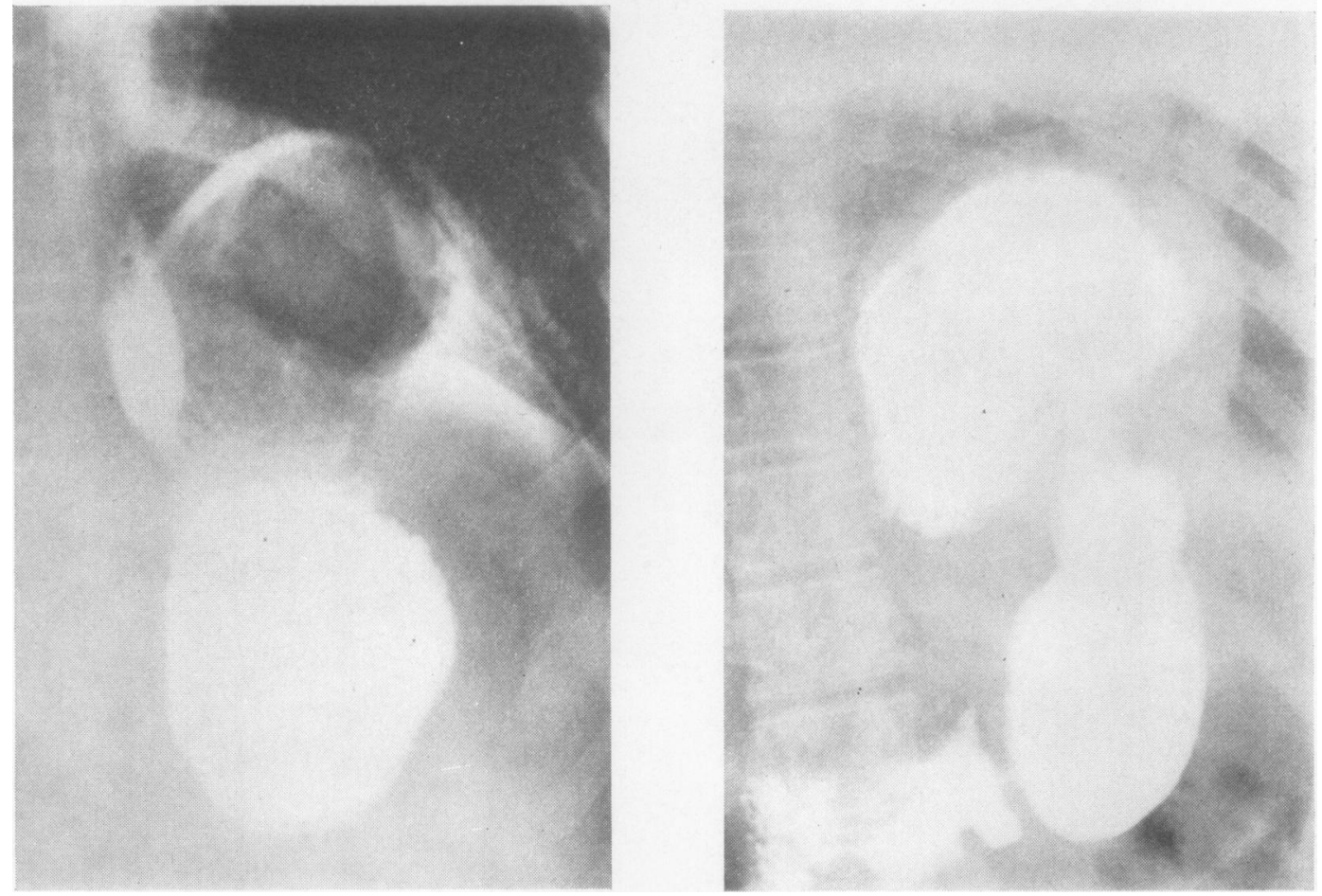

FIGS 4 and 5. Case 3. Barium meal showing partial torsion of the herniated stomach. The cardia is below the diaphragm.

by distension following a large meal. In this and the previous case both patients presented as an acute upper abdominal emergency for which a laparotomy was done unnecessarily. Extralobar bronchopulmonary sequestration is often associated with a diaphragmatic hernia, suggesting a common developmental error. Valle and White (1947) found this was so in $29.7 \%$ of cases.

CASE 4 STRANGUlated hiatus herNia A housewife of 66 years was admitted to a general medical ward with a history of sudden and severe epigastric and retrosternal pain after eating a large meal.

She had previously had a cholecystectomy and two years earlier had been treated for coronary thrombosis. One year previously she had been admitted with epigastric pain and vomiting resembling her present attack but less severe. A barium meal then showed a hiatus hernia containing distended stomach but without obstruction. As she also had abdominal tenderness her appendix was removed but was found to be normal. Her acute symptoms then subsided until the present attack.

On admission she was found to be very shocked, with epigastric tenderness, and was vomiting coffeecoloured fluid. She was treated conservatively with gastric suction and intravenous fluids. On the third day a chest radiograph (Fig. 6) showed distension and fluid levels in both the thoracic and abdominal portions of the stomach. The obstruction persisted with occasional vomiting and persistent retching, and a film taken on the eleventh day (Fig. 7) showed an enormously dilated stomach with retention of barium. After this she began to improve and a barium meal on the sixteenth day (Fig. 8) showed no obstruction.

I found at thoracotomy a large paraoesophageal hernia with torsion of the stomach. The hernial sac and its contents were adherent to the surrounding structures and to the hiatal orifice. The hernia was repaired and her subsequent progress was uneventful.

Comment Acute obstruction of the stomach is not such an unusual complication of paraoesophageal herniae. It usually resolves with conservative treatment, but occasionally progresses to gangrene and perforation. The severity of the clinical symptoms in this patient on admission suggested that transient strangulation may have occurred. This last attack could have been prevented and the patient saved much suffering if the hernia had been repaired when first diagnosed.

\section{MECHANISM OF STRANGULATION}

Strangulation in every type of diaphragmatic hernia is due to interference with the blood supply 


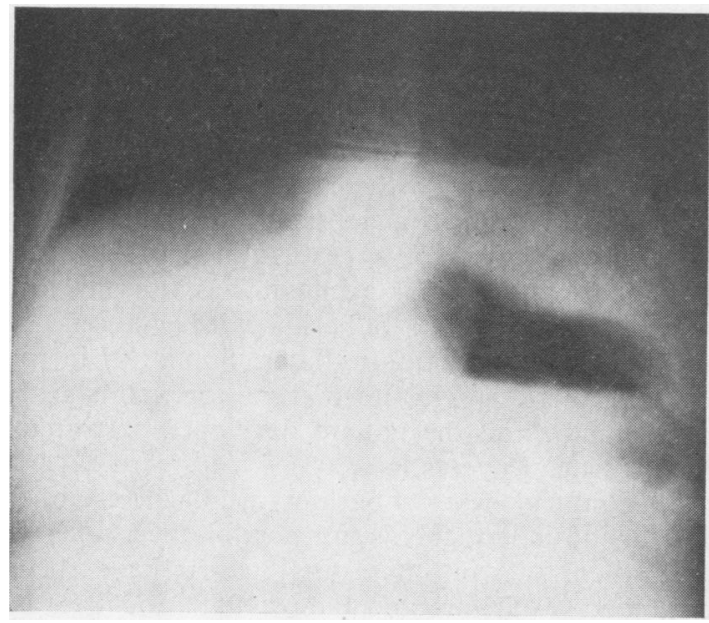

FIG. 6. Case 4. Air-fluid levels and distension in both the thoracic and abdominal portions of the stomach.

of the prolapsed viscus.

Predisposing causes are a small orifice, torsion of the stomach, the absence of a sac, and the presence of adhesions.

The precipitating factor in every case is either a sudden increase of the pleuroperitoneal pressure gradient or acute distension of the incarcerated viscus, or frequently both. This combination of factors occurs most commonly after the ingestion of a large meal or copious quantities of fluids. This was so in three of my four cases. The onset

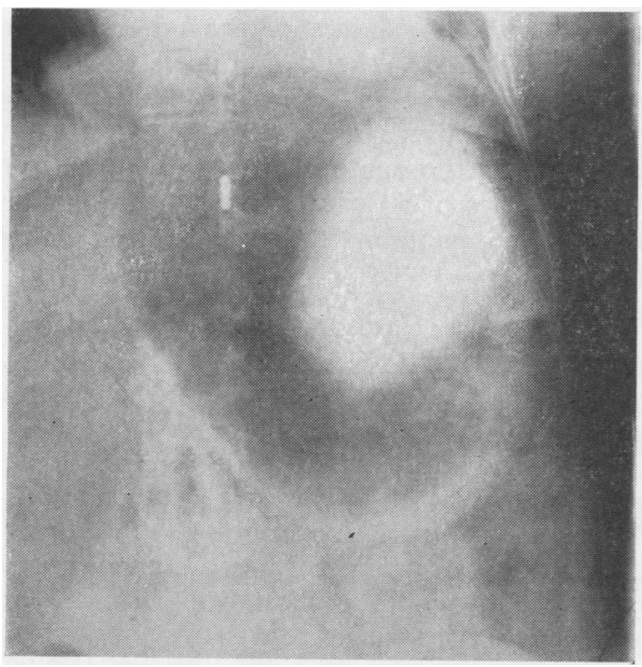

FIG. 7. Case 4. Grossly dilated stomach with retention of barium. is often delayed until after the patient has retired to bed ; and Marchand (1957) has demonstrated that the intragastric pressure is higher in the recumbent position. Strangulation has been described following a sudden rise of intra-abdominal pressure due to vomiting, retching, straining at stool, or a blow on the abdomen.

The sustained rise of intra-abdominal pressure associated with the late stages of pregnancy make these patients especially liable to strangulation, particularly during delivery. Pearson (1953) found reports of six patients who died of a strangulated diaphragmatic hernia in pregnancy, and described a case of strangulation several hours after normal delivery. The first to operate successfully on such a case were Thompson and Le Blanc (1945). I have found reports of a further seven cases of acute obstruction or strangulation during pregnancy since 1953. These cases suggest that repair of a diaphragmatic hernia should not be delayed during the child-bearing period.

\section{DIAGNOSIS}

Cases of strangulated diaphragmatic hernia are best treated in a thoracic surgical unit but are often initially admitted to general medical or surgical wards, and the condition may be missed because it has not been considered in the differential diagnosis. A careful history should be taken to exclude old trauma (case 2) and inquiry should be made for symptoms of diaphragmatic herniation.

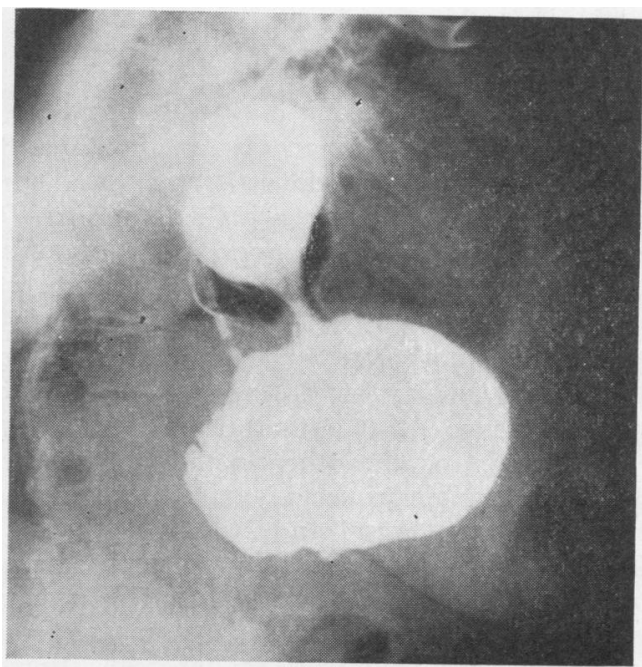

FIG. 8. Case 4. Free passage of barium from the thoracic to the abdominal portions of the stomach. 
SYMPTOMS These are generally sudden and progressive. The most important feature is lower chest or epigastric pain so severe that it may be mistaken for a perforated peptic ulcer (cases 2 and 3 ). Left shoulder pain is present in $10-20 \%$ of cases. If the stomach alone is involved the patient vomits small amounts and continues to retch without significant relief. If intestines alone are involved the symptoms are those of high or low intestinal obstruction, depending on the site of strangulation. Where there is prolapse of both stomach and intestines (e.g., many congenital and traumatic herniae) the symptoms due to strangulation of the stomach dominate the clinical picture (cases 1 and 2). If gastric distension or massive herniation are present there will be shortness of breath.

PHYSICAL SIGNS On inspection there may be evidence of past trauma. Respiratory movements on the affected side are diminished or absent. If the stomach and intestines have prolapsed into the chest the abdomen will be flat or scaphoid, but if the colon alone is involved there will be distension.

There is often upper abdominal tenderness and guarding suggesting peptic perforation (cases 2 and 3). Bowel sounds may be heard in the chest and there are frequently signs of mediastinal displacement. Severe shock and cardiovascular collapse often dominate the clinical picture (cases 1 to 4$)$.

RADIOLOGICAL APPEARANCES The most important aid to diagnosis is an antero-posterior radiograph of the chest taken in the upright position. It can be misinterpreted ; the correct diagnosis was made in only 16 out of 21 cases in Carter and Giuseffi's series (1948). The commonest error in a small hernia is to mistake it for a high diaphragm. An opacity, air-fluid levels, or poor definition of the diaphragmatic outline should be viewed with suspicion. A large gastric hernia can be confused with a pneumothorax or hydropneumothorax (case 1), but it may be distinguished from these by the presence of two fluid levels, one in the pleural cavity and the other in the stomach, and it is often possible to see a small apical mass of compressed lung (Figs 1 and 2).

The heart shadow can obscure gastric herniation through the oesophageal hiatus. This occurred in Sheridan's case (1955), a laparotomy was done and nothing was found, the gangrenous stomach being resected successfully through a thoracotomy 24 hours later. If intestines have prolapsed into the chest, abnormal opacities and air pockets are $\frac{\bar{C}}{0}$ visible.

The chest radiograph may sometimes be quite $\vec{\varnothing}$ normal immediately after a traumatic rupture of the diaphragm. It is thought that this is due to ${ }^{\infty}$ temporary sealing of the rent by omentum or a $\vec{O}$ solid viscus, or to a reducible hernia. Hurley $\vec{\perp}$ (1953) describes such a case in which the chest $\omega_{\sigma}$ radiograph after a car accident was normal, and $\stackrel{2}{\overrightarrow{2}}$ the patient developed a hernia with gangrene of $\underset{\text { ( }}{\times}$ the stomach eight months later. Similarly, in my $\omega$ case 3 , there was a normal radiograph shortly or after injury, and the patient developed a strangu- $\rightarrow$ lated hernia 15 years later.

In doubtful cases a barium meal will establish the diagnosis, but this is not possible in a severely $\vec{c}$ ill patient. Two interesting cases have been $\mathbb{D}$ described by Sellors and Papp (1955) and Beardsley and Thompson (1964). They each described a patient who had a paraoesophageal hernia with $\stackrel{\Phi}{-}$ gastric obstruction and partial torsion and was $\vec{\bullet}$ given barium: the obstruction was seen to resolve $\underset{\infty}{\mathscr{D}}$ during examination.

\section{COMPLICATIONS}

The most serious complications are gangrene and $\frac{\text { के }}{\varnothing}$ perforation of the prolapsed stomach or intestines. Bosher, Fishman, Webb, and Old (1960) reported $\overrightarrow{\overrightarrow{0}}$ 19 cases from the literature with gangrene and perforation of the stomach, some discovered at operation and others at necropsy. Of these, $10 \stackrel{.}{-}$ were traumatic, seven hiatal and parahiatal, and $\vec{\sigma}$ two posterolateral congenital herniae. Gangrene occurred within 48 hours of the onset of symp- $x$ toms in six cases. The diagnosis is easily over- $\frac{3}{3}$ looked, since in five of these patients the condition was only recognized at necropsy and in a further $\frac{3}{3}$ four not until thoracotomy.

In this series of 64 cases from the recent literature (1953-66) gangrene was present in 35 patients $\frac{7}{0}$ $(54.9 \%)$.

\section{TREATMENT}

Resuscitative measures are often necessary, but the patient should be operated on as soon as is practicable. It is important to decompress the dis- 0 tended stomach pre-operatively, preferably with $\stackrel{\odot}{\odot}$ a Ryle's tube, but if this is not possible and the $\stackrel{\infty}{+}$ patient's condition is critical, drainage may be 0 established through the chest wall with an inter- ${ }_{0}$ costal tube or a trocar and cannula. This will $\stackrel{\otimes}{\circ}$ often produce enough improvement to allow $\overrightarrow{\mathbb{D}}$ operative treatment, and proved to be a life-saving procedure in two of our patients (cases 1 and 2). 
The preferred approach is by a thoracotomy, because the prolapsed viscera are often adherent, the distended stomach or intestine can be decompressed, and repair of the diaphragmatic defect is easier from above. The difficulties of an abdominal approach were shown in a case reported by McCollum and Kurtz (1955), when attempts at reduction of a distended stomach resulted in a tear of the fundus, $8 \mathrm{~cm}$. long, and the spilling of a large quantity of gastric contents into the peritoneal cavity.

A laparotomy should be done only for acute trauma where injury to abdominal viscera is suspected, and in these cases the diaphragm should be carefully inspected for possible tears. Robb, Pollock, and Seright (1966) reported two fatalities due to strangulation through an undiagnosed diaphragmatic tear. Both patients had had a laparotomy, one with a splenectomy and the other with repair of a ruptured liver.

If resection is required a thoracotomy can be extended into a thoraco-abdominal incision.

Table III shows the mortality in 64 cases of strangulated diaphragmatic hernia reported between 1953 and 1966 .

\section{T A B L E I I I}

MORTALITY IN 64 CASES OF STRANGULATED DIAPHRAGMATIC HERNIA (1953-66)

\begin{tabular}{c|c|c|c|c|c|c|c}
\hline $\begin{array}{c}\text { Type of } \\
\text { Hernia }\end{array}$ & $\begin{array}{c}\text { No. of } \\
\text { Cases } \\
\text { Reported }\end{array}$ & $\begin{array}{c}\text { Death } \\
\text { after } \\
\text { Simple } \\
\text { Repair }\end{array}$ & $\begin{array}{c}\text { Death } \\
\text { follow- } \\
\text { ing Re- } \\
\text { section }\end{array}$ & $\begin{array}{c}\text { Too Ill } \\
\text { for } \\
\text { Opera- } \\
\text { tion }\end{array}$ & $\begin{array}{c}\text { Discov- } \\
\text { ered at } \\
\text { Nec- } \\
\text { ropsy }\end{array}$ & $\begin{array}{c}\text { No. } \\
\text { Mortality }\end{array}$ & $\%$ \\
\hline $\begin{array}{c}\text { Congenital } \\
\text { Traumatic }\end{array}$ & 4 & 1 & - & - & - & 1 & 25 \\
Hiatal. & 27 & 3 & 5 & 1 & 4 & 13 & $48 \cdot 1$ \\
Incisional & 7 & 2 & 4 & 3 & - & 9 & 34.6 \\
\hline Total & 64 & 6 & 10 & 4 & 4 & 24 & 37.5 \\
\hline
\end{tabular}

\section{REFERENCES}

Allison, P. R. (1962). Surgery of the Chest, p. 269. Ed. by J. Gibbon, Jr. Saunders, Philadelphia and London.

Beardsley, J. M., and Thompson, W. R. (1964). Acutely obstructed hiatal hernia. Ann. Surg., 159, 49.

Belsey, R. (1965). Clinical Surgery, vol. V, Thorax, p. 381, ed. A. L. d'Abreu. Butterworths, London.
Bernatz, P. E., Burnside, A. F., and Clagett, O. T. (1958). Problem of the ruptured diaphragm. J. Amer. med. Ass., 168, 877.

Bingham, J. A. W. (1959). Herniation through congenital diaphragmatic defects. Brit. J. Surg., 47, 1.

Bosher, L. H., Fishman, L., Webb, W. R., and Old, L. (1960). Strangulated diaphragmatic hernia with gangrene and perforation of the stomach. Dis. Chest, 37, 504.

Carlson, R. I., Diveley, W. L., Gobbel, W. G., and Daniel, R. A (1958). Dehiscence of the diaphragm associated with fractures of the pelvis or lumbar spine due to nonpenetrating wounds of the chest and abdomen. J. thorac. Surg., 36, 254.

Carter, B. N., and Giuseffi, J. (1948). Strangulated diaphragmatic hernia. Ann. Surg., 128, 210.

Childress, M. E., and Grimes, O. F. (1961). Immediate and remote sequelae in traumatic diaphragmatic hernia. Surg. Gynec. Obstet., $113,573$.

Comer, T. P., and Clagett, O. T. (1966). Surgical treatment of hernia of the foramen of Morgagni. J. thorac. cardiovasc. Surg., 52, 461.

Coppinger, W. R. (1960). Rupture of diaphragm following repair of hiatal hernia. Arch. Surg., 80, 998.

Effler, D. B. (1965). Allison's repair of hiatal hernia: late complication of diaphragmatic counterincision and technique to avoid it. J. thorac. cardiovasc. Surg., 49, 669.

Harrington, S. W. (1948). Various types of diaphragmatic hernia treated surgically. Report of 430 cases. Surg. Gynec. Obstet., 86 735. Hurley, G. A. P. (1953). Strangulated hiatus hernia. Ann. Surg., 138,

Keshishian, J. M., and Magovern, G. J. (1958). Dehiscence of the stomach through a counterincision in the diaphragm following repair of a hiatus hernia. Ibid., 148, 276

Kirkland, J. A. (1959). Congenital posterolateral diaphragmatic hernia in the adult. Brit.J. Surg., 47, 16

Knight, C. D., and McCook, W. W. (1960). Traumatic diaphragmatic hernia. Amer. Surg., 26, 656.

McCollum, E. B., and Kurtz, E. J. (1955). Incarcerated hiatus hernia with cryptic perforation of the stomach. Amer. J. Surg., 90, 1031.

Marchand, P. (1957). A study of the forces productive of gastro-oesophageal regurgitation and herniation through the diaphragmatic hiatus. Thorax, 12, 189.

Moos, D. J. (1956). Traumatic diaphragmatic hernia with strangulation and gangrene of the stomach. Minn. Med., 39, 795.

Pearson, S. (1953). Strangulated diaphragmatic hernia. Arch. Surg., 66, 155 .

Pilcher, R. S. (1965). Clinical Surgery, vol. V, Thorax, ed. A. L. d'Abreu, p. 386. Butterworths, London.

Rickham, P. P. (1955). Strangulated diaphragmatic hernia in the neonatal period. Thorax, $10,104$.

Robb, W. A. T. Pollock, R. M., and Seright, W. (1966). Traumatic diaphragmatic hernia. J. roy. Coll. Surg. Edin., 12, 53.

Sellors, T. H., and Papp, C. (1955). Strangulated diaphragmatic hernia with torsion of the stomach. Brit. J. Surg., 43, 289

Sheridan, J. T. (1955). Incarcerated diaphragmatic hernia with gangrene of the stomach. Surgery, 38, 741 .

Sullivan, R. E. (1966). Strangulation and obstruction in diaphragmatic hernia due to direct trauma. J. thorac. cardiovasc. Surg.,

Sutherland, H. D. (1958). Indirect traumatic rupture of the diaphragm. Postgrad. med. J., 34, 210.

Thompson, J. W., and Le Blanc, L. J. (1945). Congenital diaphragmatic hernia: visceral strangulation complicating delivery. Amer. J. Surg., 67, 123.

Valle, A. R., and White, M. L., Jun. (1947). Subdiaphragmatic aberrant pulmonary tissue. (Case report.) Dis. Chest, 13, 63 . 